Volume, 14, n. 1, ano, 2018

\title{
INDÍCIOS, PISTAS E SINAIS: INTERLOCUÇÃO ENTRE PROFESSOR E BEBÊ NA CRECHE
}

\author{
José Ricardo Silva ${ }^{1}$ \\ José Milton de Lima
}

\begin{abstract}
RESUMO De modo geral, os bebês nas creches são vistos como seres passivos e incapazes. Tais concepções desencadeiam práticas de cunho assistencialistas, focadas na higiene, alimentação, sono e a proteção. Temos clareza da necessidade e importância de práticas voltadas ao cuidado do bebê, porém insuficientes para garantir o desenvolvimento infantil em suas máximas possibilidades. De natureza teórica, o objetivo deste texto é apresentar e discutir, à luz da teoria histórico-cultural, o bebê, como herdeiro de um sistema nervoso que lhe permite ser ativo nas relações que estabelece e, assim, emitir indícios, pistas ou sinais de suas necessidades internas, portanto, passíveis de serem captadas e atendidas pelo olhar atento do professor interessado em contribuir com o seu desenvolvimento. Nesta direção, destacamos a postura e o olhar do professor que ao dirigir sua atenção ao bebê e suas manifestações, capta indícios que o auxiliem no planejamento das vivências promotoras do desenvolvimento infantil. Por fim, concluímos que essas manifestações convidam os professores a estabelecer interlocuções com os bebês que atendem na creche. Acolher e atender as necessidades internas dos bebês significa coloca-los no centro do planejamento pedagógico.
\end{abstract}

Palavras-chave: Bebês. Sinais. Práticas pedagógicas.

\section{INDICES, TRACKS AND SIGNS: INTERCONNECTION BETWEEN TEACHER AND BABY IN DAY CARE CENTER}

SUMMARY In general, babies in day-care centers are seen as passive and incapable beings. Such conceptions trigger welfare practices, focused on hygiene, food, sleep and protection. We are clear about the need and importance of practices aimed at the care of the baby, but insufficient to guarantee child development in its maximum possibilities. Of theoretical nature, the objective of this text is to present and discuss, in the light of historical-cultural theory, the baby, as heir of a nervous system that allows him to be active in the relations he establishes and thus to emit clues, clues or signs of their internal needs, therefore, capable of being captured and attended to by the attentive look of the teacher interested in contributing to their development. In this direction, we highlight the posture and the eyes of the teacher who, when directing their attention to the baby and its manifestations, pick up indications that help him in the planning of the experiences that promote child development. Finally, we conclude that these manifestations invite teachers to establish interlocutions with the babies who attend the day care. Welcoming and meeting the inner needs of babies means putting them at the center of pedagogical planning.

\footnotetext{
${ }^{1}$ Licenciado em Educação Física e Pedagogia, Mestre em Educação e Doutor em Educação pelo Programa de Pós-graduação da Faculdade de Ciências e Tecnologias, UNESP, Presidente Prudente - SP. Professor no curso de Educação Física na Faculdade de Presidente Prudente (FAPEPE). E-mail: ricardo.unesp@hotmailcom.

${ }^{2}$ Licenciado em Educação Física e Pedagogia, Mestre em Educação e Doutor em Educação pelo Programa de Pós-graduação da Faculdade de Filosofia e Ciências, UNESP, Marília - SP. Professor adjunto no Departamento de Educação na Faculdade de Ciências e Tecnologias, UNESP, Presidente Prudente - SP.
} 
Volume, 14, n. 1, ano, 20118

Key-words: Babies. Signals. Pedagogical practices.

\section{INTRODUÇÃO}

O bebê humano é um dos únicos filhotes do reino animal que depende de seus cuidadores por um período muito longo. Diferentemente de outros filhotes mais autônomos, esta situação de dependência se dá devido à sua condição de que outro lhe proteja e alimente. Além disso, o bebê humano encontra-se numa situação na qual não possui a capacidade eminentemente humana de comunicação, a fala articulada, isto reforça sua dependência da relação com o outro mais desenvolvido para se apropriar das objetivações humanas. Sendo assim, em seus primeiros anos de vida, é o adulto quem 'escolhe', de forma consciente ou não, o conteúdo e a forma pela qual o bebê entrará em contato com a realidade objetiva. Portanto, na compreensão de Vigotski (2006), o bebê encontra-se em contradição, entre a máxima sociabilidade com o entorno, contudo, suas condições de comunicação são mínimas. Frente a esta contradição é que desponta a relação com os adultos, tal como afirmam Mukhina (1996) e Elkonin (2009), como a atividade humana que mais contribui para o desenvolvimento dos bebês nos primeiros meses.

De acordo com Mukhina (1996), todo desenvolvimento do bebê depende das relações com os indivíduos mais experientes: o próprio desenvolvimento biológico, andar, utilizar os objetos, falar, pensar, se controlar, etc. Não só as ações práticas, como também os atos psíquicos são resultados da aprendizagem com a sociedade. Portanto, o adulto é quem porta e oferece os objetos e informações necessárias para que o bebê se desenvolva, se humanize. Nesta relação, o adulto empresta sua consciência ao bebê para que, ao longo dos anos, possa desenvolver sua autonomia. Somente por meio da convivência em sociedade e do papel diretivo do adulto é que o bebê conseguirá ao logo do tempo, apropriar-se das objetivações humanas. Esta concepção de desenvolvimento humano nos permite afirmar que, a atuação do adulto com o bebê torna-se condição para o seu processo de humanização.

Contudo, ao voltarmos nossa atenção para a relação adulto-criança em âmbito institucional, ou seja, em instituições de Educação Infantil, constatamos diversos problemas que não possibilitam o desenvolvimento infantil tal como preconizam, em 
Volume, 14, n. 1, ano, 20118

geral, documentos educacionais, propostas curriculares e pesquisas. Para além de todos os problemas que amargam esta etapa da Educação Básica, notavelmente as práticas pedagógicas desenvolvidas com bebês nas creches, são as que mais carecem de preocupação. No que concerne às práticas educativas desenvolvidas com os bebês nas creches, podemos destacar algumas pesquisas que se preocuparam com este cenário.

Campos, Füllgraf, Wiggers, (2006) analisaram dados obtidos por meio de levantamento sobre resultados recentes de pesquisas empíricas acerca da qualidade da educação nas instituições brasileiras de educação infantil, divulgadas entre 1996 e 2003. Em relação às creches destacam: creches ainda vinculadas à Assistência Social; falta de vagas para atender os bebês, o que ocasiona na busca por creches não conveniadas e domiciliares, atendimento com características assistencialista; os bebês entendidos como frágeis, carentes e dependentes; bebês em longos períodos sem intervenção; salas sem atrativos, sem almofadas ou tapetes, sem cantinhos para atividades, insalubres e com problemas de segurança; materiais guardados longe do alcance das crianças, de funcionamento precário; a criança desconsiderada no planejamento das práticas a serem desenvolvidas; muitos municípios não possuíam propostas pedagógicas para os bebês e, quando possuem, abrangem apenas aspectos de higiene, alimentação e saúde; a influência de outros países na organização das práticas pedagógicas; diversidade das características do profissional que atua com bebês, profissional com baixa escolaridade; desvalorização salarial; hierarquias entre as próprias trabalhadoras da creche (professora, monitora e etc.); problema na compreensão sobre o cuidar, educar e a antecipação da escolarização; confusão por parte dos professores entre o espaço da creche e o doméstico; o despreparo do professor em relação à questões sobre saúde, gênero e sexualidade das crianças; a creche como favor aos pais que trabalham; distanciamento na relação escola-família; visão estereotipadas e preconceituosas em relação às famílias.

Sobre o processo de formação, Borges (2009) constatou que professoras formadas no curso de Magistério ou até mesmo de Pedagogia, em nível superior, não recebem a qualificação necessária para desenvolver seu trabalho educativo, principalmente com as crianças menores atendidas em tempo integral nas creches. Pontuou, também, a relevância de cursos direcionados aos professores de creche, já que demonstraram inicialmente desconhecimento sobre as especificidades do 
Volume, 14, n. 1, ano, 20118

desenvolvimento infantil de 0 a 3 anos, sobre os conteúdos e trabalho pedagógico a ser desenvolvido, o que retrata que a formação inicial das professoras é insuficiente em relação às disciplinas que abordem teorias e práticas pedagógicas referentes à creche.

Ramos (2011) problematiza a histórica concepção que coloca o bebê numa posição de incompetência, subordinação e preparação para a vida adulta e a necessidade de entendê-lo como capaz. Já Birchal (2010) aponta que a criança pequena é vista como sujeito passivo, desprotegido e, então, o atendimento é reduzido às suas necessidades físicas, sono, fome, higiene. Adverte para a falta de ambientes capazes de propiciar segurança e oportunidades de explorações. Silva (2008) constatou que o trabalho docente ainda está mais voltado para questões assistenciais do que educativas. Costa (2006) cita que, ao visitarmos creches, deparamo-nos com profissionais preocupados com os cuidados básicos de saúde, alimentação, bons hábitos e ênfase em atividades recreativas.

Como visto, de modo geral, a problemática identificada se volta para concepções que colocam o bebê como um ser passivo e incapaz, soma-se a isso, a precária formação inicial sobre a temática, o que desencadeia práticas de cunho assistencialistas, preocupadas apenas com a higiene, alimentação, sono, saúde, com as necessidades físicas, proteção e, consequentemente, pouco contribuem para o seu desenvolvimento ontológico em suas máximas possibilidades.

Temos clareza da necessidade e importância de práticas voltadas às necessidades vitais do bebê, porém insuficientes para garantir amplo desenvolvimento infantil. Neste cenário, as práticas desenvolvidas com os bebês nas creches, se aproximam em muito com os afazeres domésticos, portanto, passíveis de serem questionadas e de serem substituídas pelo próprio lar em situações onde as mães não precisem trabalhar fora de casa.

Por outro lado, acreditamos que esta problemática pode ser inicialmente superada quando o modo como os professores olham e compreendem o bebê suplanta concepções que o coloquem como passivos nas relações com o entorno e passem a considera-los em suas especificidades. Neste sentido, a discussão teórica que aqui se arvora, à luz da teoria histórico-cultural, procura apresentar o bebê, herdeiro de um sistema nervoso complexo que, quando em relação com o entorno, desenvolve-se e lhe permite ser e estar ativo em suas relações e emitir indícios, pistas ou sinais de suas 
REVISTA ELETROONICA

He Hiarius

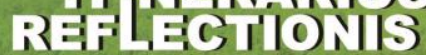

Volume, 14, n. 1, ano, 20118

necessidades internas, representativos da situação social de desenvolvimento em que se encontra, logo, passíveis de serem captados e atendidos pelo olhar atento do professor interessado em contribuir com o seu desenvolvimento. Vigotski (2006) entende a situação social de desenvolvimento como uma combinação de processos internos, conquistas históricas do sujeito, com processos externos. Desse modo, em cada idade, a relação estabelecida entre a criança e o entorno é totalmente peculiar e única. Este é o ponto crucial para todas as mudanças qualitativas no desenvolvimento. Todavia, não podemos nos ater a etapa real, já alcançada. Preocupados com o desenvolvimento humano, precisamos olhar para o desenvolvimento que está por vir, em vias de se estruturar, os processos que ainda não se consolidaram. Para tanto, estes profissionais devem exercitar o olhar atento para os indícios, pistas ou sinais externalizados pelos bebês em demonstração de suas necessidades e interesses e incidir sobre as neoformações.

Todavia, não basta somente observar aquilo que fazem os bebês. Faz-se necessário que os professores adotem a postura de investigadores das minúcias e lancem mão de 'lentes' teóricas para saberem o que observar e identificar as pitas emitidas pelos bebês. É deste modo que estamos pensando o trabalho do professor na creche, um investigador que sabe observar e identificar os sinais emitidos pelos bebês para, então, organizar vivências promotoras do desenvolvimento infantil.

A partir desta trama, o objetivo deste texto é defender o bebê como indivíduo ativo em suas relações com o entorno e emissor de indícios, pistas ou sinais representativos de suas necessidades internas passíveis de serem observadas e captadas pelo professor preocupado em promover o desenvolvimento em curso.

\section{O OLHAR INVESTIGATIVO NO CONTEXTO DA CRECHE.}

O olhar que estamos convidando os professores a desempenharem no contexto da creche é um olhar centrado nos detalhes, nos elementos pouco notados, àqueles que poderiam passar despercebidos pela maioria das pessoas e que podem ser reveladores. A ideia aqui é que esta postura pode orientar os professores nos momentos de observação à procura dos indícios externos lançados pelos bebês de modo a auxiliar no processo educativo, portanto, um olhar que consiga ver, enxergar, ler e compreender a forma 
Volume, 14, n. 1, ano, 20118

como o bebê capta o mundo em sua volta e externaliza suas necessidades e interesses através de diferentes manifestações.

Ser professor de bebês, portanto, nos direciona a um modo diferenciado de se colocar e comportar mediante as manifestações assistidas. Um olhar investigativo que precisa valorizar e captar as informações necessárias por um viés comunicativo que não prioriza a fala justamente devido a sua ausência. Torna-se necessário captar as informações necessárias para a promoção do desenvolvimento em questão de outras formas, através de indícios emitidos pelos bebês.

Esta premissa, captar indícios, não nos é particular, outros autores já orientaram para esta direção ao problematizarem a temática bebê em creches. Mesmo utilizando outras bases teóricas, estes pesquisadores, nos orientaram e reforçam a ideia de que no trabalho com os bebês, é preciso estar atento e 'ouvir o que eles têm a nos dizer'.

Dagnoni (2012) buscou capturar o ponto de vista dos bebês por meio de suas possibilidades expressivas não-verbais, suas intenções, interesses e necessidades, ao partilhar significados pelos meios funcionais de que dispõem, mesmo na ausência da fala articulada em situações cotidianas. Para Guimarães (2006), os professores precisam tomar os bebês como ponto de partida. Para isto, basta observar e registrar suas iniciativas comunicacionais, por exemplo, as brincadeiras que inventam, a forma como se engajam na realidade circundante, a imitação (por iniciativa própria) são indícios que revelam intensa disponibilidade para o contato, a troca e para o aprender com o outro.

Também nesta direção, Eltink (2000) procurou apresentar e discutir indícios (sinais, pistas) de que crianças com menos de dois anos de idade ofereciam aos educadores de berçário como suportes para a avaliação da adaptação na creche, por exemplo, o sorriso, o choro, dormir ou não dormir, agarrar na mãe, chamar pela mãe, reagir contra a aproximação da professora ou aceitar o seu colo, fugir dela ou aceitar sua aproximação, reações de protesto à separação dela ou busca de proximidade, reações de estranhamento a ela ou a sua ausência, entre outros, pode ajudar os educadores a refletir acerca do processo de adaptação dos bebês e das famílias à creche.

Guimarães (2008) observou como os bebês constituem sentidos no olhar, na imitação, oferta de objetos, e outras diferentes formas de contato e troca com adultos e com outros bebês. De acordo com Mendes e Moura (2009), nas últimas três décadas, diversos trabalhos foram realizados com $\mathrm{o}$ intuito de entender melhor $\mathrm{o}$ 
Volume, 14, n. 1, ano, 20118

desenvolvimento emocional dos bebês e, para isso, levaram em conta suas expressões faciais. De acordo com Pantalena (2010) é preciso acolher as expressões do bebê para identificar as suas necessidades.

Pois bem, tais ideias convocam um olhar atento por parte dos adultos que trabalham com bebês, um olhar que busca enxergar além do aparente pois os sinais emitidos indicam algo e precisam ser considerados no planejamento e na ação pedagógica. Portanto, os indicativos teóricos que apresentaremos a seguir sugerem que olhemos para os bebês como seres ativos em suas relações e capazes de emitirem sinais ou pistas que indiquem seus interesses e necessidades internas. Por isso, é preciso saber o que e como olhar para o bebê. Este olhar para as pistas deixadas pelo bebê não poderá ater-se em sua superficialidade, um olhar rápido que não consiga significá-lo. Isto significa, também, considerar sob que circunstâncias estes sinais são emitidos. Somente assim, poderemos orientar nossa postura como investigadores das necessidades internas dos bebês e, então, considera-los como protagonistas no planejamento e na ação pedagógica. Acreditamos que este indicativo pode influenciar os professores a captarem indícios, pistas e sinais emitidos pelos bebês e, então, organizarem vivências de acordo com seus interesses e necessidades internas.

\section{INDÍCIOS, PISTAS E SINAIS REPRESENTATIVOS DA SITUAÇÃO SOCIAL DE DESENVOLVIMENTO DOS BEBÊS.}

Antes de nascer, o feto tem o seu desenvolvimento assegurado pela mãe por via do cordão umbilical. Após o nascimento, mudanças drásticas ocorrem em seu modo de respirar e alimentar. O bebê se depara com novas condições de vida, diferente da vida intrauterina. $\mathrm{O}$ choro do bebê na sala de parto, por exemplo, marca a adaptação muscular dos primeiros reflexos de respiração via pulmonar, em outros momentos, gritos e choros serão os primeiros indícios que sinalizarão sensações de mal-estar, fome e incômodos. Estes sinais sinalizam necessidades básicas de alimentação e cuidado, necessidades de primeira ordem e, quando captados por seus adultos cuidadores, são atendidos prontamente.

Sua primeira semana de vida, é marcada pela vigília e pelo sono, um estado semi-sonolento, isolando-se quase que totalmente em relação ao mundo. Passado cerca de 45 dias após o nascimento, período de passividade, transição entre a vida intrauterina 
Volume, 14, n. 1, ano, 20118

e a vida social, desponta no bebê grande interesse pelo mundo a sua volta, inicia-se o chamado período de interesse receptivo (VIGOTSKI, 2006; MARTINS, 2009).

Será por volta do segundo mês de vida que o bebê apresentará uma forma especial de atividade, uma atividade de comunicação emocional. A reação que aparece nesta fase do bebê mediante a relação com o adulto é, para esta teoria, uma relação complexa que objetiva o contato através de seus próprios meios: o olhar, o tato, o sorriso e as manifestações de movimento. Este afeto que o adulto causa no bebê, afirma Gomes (2013), não natural e espontâneo, mas estimulado na relação estabelecida por ambos. A autora explica que

Essa relação cria no bebê uma necessidade que ele não tinha até então e que passa a ter a partir do contato e das sucessivas aproximações que estabelece com o adulto; a necessidade do "outro" é, portanto, uma necessidade socialmente criada (GOMES, 2013, p. 513).

Neste período, é o adulto que incentiva o bebê a atingir novos patamares em seu desenvolvimento, ou seja, é a relação com o adulto que afeta e move o desenvolvimento. Sobre a importância desta atividade para o desenvolvimento do bebê, Ávila (2002, p. 91) aponta que

O papel da comunicação emocional da criança com os adultos consiste basicamente em que sob a influência desta comunicação se cria na criança um estado de ânimo alegre, aumenta o tono vital geral, se consolida mais fortemente sua atividade autônoma, e todo isto em conjunto favorece o rápido desenvolvimento locomotor e sensorial da criança. (tradução nossa)

Não podemos perder de vista a característica dinâmica dos componentes cerebrais, pois serão os órgãos do sentido que organizarão os outros esquemas sensoriais. A captação do meio é favorecida através dos órgãos do sentido, analisadores (óticos, acústicos, olfativos, táteis e gustativos). Os órgãos serão as primeiras vias afetadas pelo entorno. A luz, o som, os odores, o toque, enfim, provocará reações químicas que alertarão e manterão o estado de vigília do cérebro (LURIA, 2010). Portanto, recai sobre as sensações o importante papel de iniciarem a captação das primeiras imagens reais como requisito primário na representação do mundo na consciência humana. São os órgãos dos sentidos, portanto, que farão a conexão entre o 
Volume, 14, n. 1, ano, 20118

mundo externo e o interno do bebê já que, desde o nascimento, apresentam alto grau de desenvolvimento (MUKHINA, 1996).

Desde o nascimento, os bebês apresentam um aparato biológico que lhes permitem, quando em relação com a cultura, se desenvolverem. Tal aparato possibilita ao bebê ver, ouvir, sentir, ou seja, se relacionar de múltiplas maneiras com o entorno. Por esta razão dizemos que o aparato biológico do bebê é guia de sua relação com o meio e fonte representativa de suas possibilidades. Tomando-o como base, o bebê buscará estabelecer relações com o entorno. Este desenvolvimento é decorrente da quantidade de impressões externas que o cérebro recebe a partir das experiências do bebê. Para ilustrar, ao longo do primeiro ano o cérebro do bebê cresce consideravelmente, de 150 para 950 gramas. Áreas responsáveis pela motricidade e percepção sensorial alcançam grande desenvolvimento. Porém, os setores do cérebro que não forem exercitados podem ter o desenvolvimento interrompido e até mesmo atrofiados. Se não lhe for dada as devidas condições, não há desenvolvimento, pois, as propriedades biológicas da criança não são suficientes para criar qualidades psíquicas de humanização (MUKHINA, 1996).

O bebê vê, sente e ouve que objetos compõem as ações rotineiras nas relações que estabelece com os adultos. De acordo com Elkonin (2009), esta concentração nos objetos, a atenção que o bebê dirige aos objetos em movimentos e em direções e distâncias diferentes fazem com que a convergência dos olhos e a contemplação desenvolvam-se antes dos primeiros movimentos, mas são as premissas para as primeiras tentativas. Nos primeiros meses de vida, explica Mukhina (1996) o aparelho audiovisual do bebê se torna mais preciso mediante as relações sociais. Este aperfeiçoamento termina, aproximadamente, até o quarto mês. Com este desenvolvimento, o bebê acompanha com o olhar a movimentação dos adultos e dos objetos em diferentes direções e velocidades, configurando os chamados movimentos de inciativa visual (grifos da autora). O bebê, por sua vez, responderá a estas ações externas com movimentos desordenados de braços e pernas, o complexo de animação. Para Mukhina (1996, p. 82) este tipo de movimento “(...) demarca a fronteira entre o período do nascimento e o do primeiro ano de vida". Percebe-se que o adulto, como aquele que propicia diversidade de novas impressões a serem captadas por estes órgãos do sentido, possui papel decisivo nas conquistas psíquicas em desenvolvimento. 
Volume, 14, n. 1, ano, 20118

Sob influência social, o bebê não se limitará a seguir os adultos que porta objetos do cotidiano com os olhos ou mover as mãos e os dedos apenas quando forem tocados, buscará coordenar estes dois esquemas possibilitando associar de maneira dinâmica àquilo que o afeta, olhos e mãos em uma busca visual e prática. Na primeira etapa de desenvolvimento de apreensão, é o olho que recebe as impressões externas. Por exemplo, o bebê vê um objeto, mas ainda não consegue determinar a distância nem a direção de seu alcance. Suas tentativas e erros ao tentar alcançar o objeto, orientarão suas ações futuras. "Pouco a pouco, o olho, que segue o movimento da mão, começa a captar a aproximação e o afastamento do objetivo e introduz no movimento correções constantes. " (MUKHINA, 1996, p. 96). Nesta mesma direção apontam Elkonin (2009) e Zaporózhets (1960) sobre o curso do desenvolvimento das coordenações visomotoras (olho-mão) que irão facilitar a relação entre a percepção e o comportamento, por exemplo, no ato de agarrar. Agora, a visão e os movimentos estarão intrinsecamente interligados, o bebê terá êxito ao tentar alcançar, pegar e bater nos objetos. Compondo, assim, uma unidade sensomotora do desenvolvimento.

Neste ato de pegar, a movimentação contribui para o desenvolvimento da coordenação motora e das ações dirigidas pelo bebê. É verdade que esta movimentação do bebê representa o primeiro estágio do movimento que precisa evoluir, caracterizado por gestos malsucedidos. Mukhina (1996) descreve este tipo de movimento como a primeira etapa da manipulação de objetos. Vigotski (2000), por sua vez, o denomina de gesto em si, de exploração, sem significado social.

O projeto cubano Educa su hijo, busca identificar o avanço no desenvolvimento dos bebês nos primeiros meses de vida. Para isso, utilizam quatro áreas básicas observáveis (comunicação afetiva, desenvolvimento intelectual, desenvolvimento dos movimentos e formação de hábitos). Neste momento, destacaremos os apontamentos que se referem à comunicação afetiva. Sobre este indicativo, os profissionais envolvidos buscam constatar se os bebês já podem: reconhecer o rosto das pessoas que o atendem e chorar na presença de estranhos, balbuciar e rir quando estão contentes, seguir olhando as pessoas que se movem. Para eles, estes são sinais de que o bebê está se desenvolvendo e o quanto o adulto é essencial nos primeiros meses de vida (GÓMEZ, 2002). 
Volume, 14, n. 1, ano, 20118

Sendo assim, é o adulto quem 'escolhe', de forma consciente ou não, aquilo com que o bebê entrará em contato. Portanto, o adulto, como indivíduo mais desenvolvido, é o portador das informações necessárias para que o bebê se desenvolva. Por isso, os interesses e as necessidades dos bebês estão ligados aos adultos e, logo cedo, aos objetos que os cercam. A atuação do adulto sobre o bebê torna-se um fato imprescindível para o seu desenvolvimento pois cria as premissas para o desenvolvimento da linguagem ao passo que estabelece os primeiros contatos com os objetos. Esta relação toma um caráter desenvolvente pois é somente por meio da convivência em sociedade e do papel do adulto é que o bebê poderá apropriar-se de condições que favoreçam o seu desenvolvimento psíquico.

À medida que se desenvolvem nas vivências com os adultos, surgem novas formações na estrutura da personalidade e da atividade, são mudanças psíquicas e sociais que se produzem a partir das estruturas já fixadas. Suas novas capacidades entram em contradição com as velhas formas de relação com o entorno, perde interesse pelas coisas que há pouco lhe chamavam a atenção. São, justamente estas novas formações, estas mudanças na personalidade, o critério fundamental para compreender o desenvolvimento infantil. Nesta perspectiva, o desenvolvimento marcado pela periodicidade, está em movimento revolucionário. Aparecem novas necessidades que irão dirigir a atividade do bebê (LEONTIEV, 1981).

Por isso, posteriormente à comunicação emocional com os adultos, há grande importância a atividade em conjunto com os adultos vinculadas às manipulações com os objetos. A comunicação pura e livre com os adultos que até então ocupava o lugar de linha central na promoção do desenvolvimento, não corresponde mais aos anseios do bebê, pode até mesmo aborrecê-lo, o complexo de animação decai para dar lugar a outro tipo de comunicação - a atividade em conjunto com os adultos vinculadas às manipulações com os objetos. Nestas relações em conjunto, há destaque para os objetos e brinquedos que incentivam os bebês a realizarem ações. Ocorre uma ampliação de foco e interesses do bebê, do adulto para os objetos e, mais tarde, às ações com eles (VIGOTSKI, 2006; ÁVILA, 2002).

O bebê passa a se interessar pelos objetos utilizados na relação com os adultos: os objetos utilizados no banho, na alimentação, no cotidiano, os brinquedos e etc.. Nesta viragem, os objetos ocupam o lugar de linha central e os adultos como linhas acessórias. 
Volume, 14, n. 1, ano, 20118

Ocorre, então, uma transferência de foco de interesse do bebê, do adulto para os objetos e as ações com eles demarcando a viragem de interesse do bebê, da relação emocional direta com os adultos, para a relação com os objetos mediada pelos adultos. Nessa situação social de desenvolvimento, o adulto medeia a relação do bebê com o objeto; e o objeto medeia a relação do bebê com o adulto (VIGOTSKI, 2006).

Este processo demanda muito tempo, pois torna-se necessário que o bebê tenha atingido determinada situação social de desenvolvimento para conseguir esta mudança. Este interesse está ligado às novas formações que surgem no fim do primeiro semestre e começo do segundo, afirma Zaporózhets (1987), as zonas de proteção do córtex cerebral criam premissas orgânicas para a formação das ações objetais. Quando todas as estruturas psíquicas necessárias da criança estiverem estabelecidas por uma atividade, o interesse da criança, automaticamente, passará para uma nova atividade, a manipulação aleatória dos objetos que se caracteriza como principal nesta etapa (FACCI, 2004). Por esta razão é que Leontiev (1981) explica que a princípio, a necessidade é uma condição interna do organismo. Por ser interna, a necessidade regula e ativa as correspondentes funções biológicas e a excitação geral da esfera motriz que os bebês utilizam para realizarem suas pesquisas frente aquilo que os afeta. Disso, podemos apontar que não é qualquer alvo que irá afetar, isto é, satisfazer a necessidade. Para complementar, Gomes (2008, p. 125) aponta que o afeto representa o quanto determinado "objeto preenche, no sujeito, seu poder de ser afetado, ou ainda o quanto aquele objeto/fenômeno/ideia responde ou não aos seus motivos”. Em outra publicação, Gomes (2013, p. 513) esclarece que "Nesta fase o que a atrai, controla e determina sua atenção são principalmente os objetos. " Desta forma, o bebê, motivado, buscará satisfazer sua nova necessidade - a relação, em conjunto com os adultos, com os objetos. Serão, então, os objetos que motivarão os bebês a se movimentarem, ou seja, entrarão em atividade sinalizado seu interesse pelos objetos.

Assim, pois, e isso precisa ser ressaltado de forma especial, no primeiro ano de vida não existe atitude indiferente por parte do bebê em relação aos objetos circundantes. Também, os adultos não saem de cena, mas exercem agora uma parceria com o bebê no uso dos objetos. Por isso, faz-se necessário a introdução de atividades em conjunto com os objetos, bebês e adultos. Para Elkonin (2009), a comunicação direta "criança-adulto" que serve para orientá-lo frente ao objeto, cede lugar à indireta 
Volume, 14, n. 1, ano, 20118

"criança-ações com objetos-adultos" onde a comunicação mediatiza a relação do bebê com o objeto, uma nova qualidade relacional conquistada pelo bebê. De acordo com Àvila (2002), esta nova forma de comunicação do bebê com os adultos influencia o desenvolvimento das ações com os objetos, iniciando as primeiras manipulações que tendem a se enriquecerem. O adulto é, de acordo com Elkonin (2009), o modelo responsável por afetar qualitativamente o relacionamento do bebê com as ações com os objetos. Para isso, a relação adulto-bebê passa a ser estabelecida com um novo elemento motivador das ações do bebê - os objetos e os brinquedos.

Em síntese, podemos dizer que existe no desenvolvimento do ser uma relação dialética entre o biológico e o social que, culmina na humanização do indivíduo singular, ou seja, em uma unidade, o ser humano. A condição biológica sustenta, nas devidas condições, a humanização. Esta maturação que o recém-nascido apresenta em seu sistema nervoso viabiliza o desenvolvimento do aparelho audiovisual, motor e o aperfeiçoamento das relações por meio de estímulos externos. $\mathrm{O}$ desenvolvimento destes órgãos está subjugado às relações externas. Os setores do cérebro que não forem exercitados na atividade social, podem ter o desenvolvimento interrompido e até mesmo atrofiado. Se não lhe for dada as devidas condições, não há desenvolvimento, pois, também, o desenvolvimento da visão, audição, olfato, tato e paladar condiciona-se à exposição de estímulos externos e não somente à sua base filogenética (MUKHINA, 1996). Estes indicativos teóricos precisam ser considerados, pois alerta Martins (2013, p. 126) "Sob privação de estímulos, sobretudo exógenos, o organismo substitui o estado de vigília pelo adormecimento, pela letargia, resultando em um déficit global da tonicidade cortical necessária a qualquer atividade. "Nisto reside a importância de contato emocional entre o adulto e o bebê e oferta de objetos.

Para não perdermos de vista o foco deste texto, queremos destacar o quanto o bebê emite indícios, pistas e sinais em sua relação com o entorno. De acordo com Arce e Silva (2009), ao longo dos primeiros meses de vida, é possível identificar manifestações dos bebês quando em relação com o entorno, por exemplo, o choro, o sorriso, o balbucio, as reações visuais quando fixam o olhar em objetos ou acompanham a movimentação dos adultos por perto; os movimentos desordenados de mãos e pernas quando ouvem uma voz conhecida; a relação visomotora desponta frente aos objetos desejados; o engatinhar, o andar e o falar. À medida que crescem e se desenvolvem, por 
Volume, 14, n. 1, ano, 20118

meio de seu contato com o mundo dos adultos, surgem novos interesses que mobilizam novas ações, outros indícios, sinais ou pistas. Este processo ocorre de forma gradual e revolucionária, pois cada conhecimento elaborado favorece outro e este, apoiado no anterior, faz surgir o novo, e assim sucessivamente, não de forma direta e linear, mas, dialética e contraditoriamente.

Ao captarem estes diferentes sinais emitidos pelos bebês, os professores (as) poderão planejar, organizar e avaliar as vivências que afetam o bebê, ou seja, que promovam o desenvolvimento. Nas vivências, outros indícios podem ser detectados pelo olhar investigativo do profissional. No encontro entre a vivência e a necessidade interna do bebê, um feito de objetivação, evidencia-se a coloração emocional. Leontiev (1981) aponta que neste encontro, o bebê evidencia alegria, sorriso ou até mesmo irritação e o choro quando outro bebê o atrapalha. $\mathrm{Na}$ atividade que afeta verdadeiramente o desenvolvimento, a coloração emocional marca presença.

Esta concepção, de ser ativo e comunicativo, muda radicalmente o ato educativo com o bebê, haja vista às tendências biologizantes, assistencialistas e de caráter doméstico citadas no início do texto. Não cabe, portanto, ao professor desconsiderar a capacidade do bebê de estabelecer relação ativa com o meio, mas sim, procurar estabelecer com ele uma interlocução que oriente o seu trabalho e contribua com o desenvolvimento em decurso. Ao desconsiderar estes sinais, não afeta o bebê, não promove o desenvolvimento, na perspectiva apontada.

A partir desta compreensão, fica clara a necessidade do professor, quando busca contribuir com o desenvolvimento do bebê, considerar a sua situação social de desenvolvimento e procurar pelas minúcias nos comportamentos dos bebês. Os sinais emitidos pelos bebês correspondem a sua situação social de desenvolvimento. Por isso, o modo efetivo de emitir sinais é correlato a este nível. Faz-se necessário, então, compreender o bebê como um ser ativo na relação com os adultos e em seu processo de desenvolvimento. Ao entendermos o bebê como um ser ativo e com capacidade de se desenvolverem, o professor que atua na creche compreenderá que, diferentemente do espaço doméstico, há um papel profissional a ser desempenhado. O desafio, então, é o de superar a concepção que coloca o professor em situação de espera pelo desenvolvimento do bebê que há de vir e, conceber a ideia de que o bebê está na creche 
REVISTA ELETROONICA

Hethiaitians RBज

Volume, 14, n. 1, ano, 20118

esperando pela proposta do professor, pois possui necessidades internas que requerem vivências significativas.

\section{CONSIDERAÇÕES FINAIS}

Este texto emerge a partir da concepção de professores que desconsideram as capacidades dos bebês. Disso decorre o problemático atendimento assistencialista que prioriza necessidades físicas e biológicas. Nosso intuito foi, então, apresentar subsídios teóricos que permitissem esclarecer o quão ativo são os bebês nas relações sociais e, nesta relação, emitem indícios sinais ou pistas de suas necessidades internas de acordo com a sua situação social de desenvolvimento, portanto, indicativos para que professores (as) possam planejar, organizar, sistematizar e até mesmo avaliar as suas propostas pedagógicas. .

Nesta mesma direção Ramos (2011) aponta que, o trabalho de escuta e atenção às possibilidades expressivas do bebê emergem como possibilidade para que a professora conheça os modos próprios de pensar e a versatilidade de ações sócio comunicativas empreendidas para partilhar seus desejos, necessidades e intenções como elementos contextualizadores da organização didática. "Continuamente, o professor precisa observar e realizar intervenções, avaliar e adequar sua proposta às necessidades, desejos e potencialidades do grupo de crianças e de cada uma delas em particular." (BARBOSA, 2010, p. 6)

Acolher e atender as necessidades e interesses dos bebês significa estabelecer interlocução e colocá-los no centro do planejamento pedagógico. Esta interlocução pode ser construída a partir destes sinais. Entender os bebês significa, como afirmam Delgado e Nornberg (2013), observá-los e escutá-los mais para construirmos um movimento de abertura aos seus pontos de vista, suas potencialidades e seus desejos. Cada bebê é único, cada situação social de desenvolvimento é única. Os bebês querem, eles nos 'dizem' o que querem, o que necessitam, basta 'ouvi-los'. A teoria históricocultural nos auxilia enxergar o choro, os movimentos das mãos, do globo ocular e da cabeça, o balbucio e o sorriso como sinais emitidos pelos bebês mediante os afetos causados por nós e pelos objetos. Estes sinais, por sua vez, não podem ser vistos como manifestações ao acaso, pois máquinas emitem sinais sonoros e luminosos, uma árvore move os seus galhos sob a influência das forças do tempo. 
Volume, 14, n. 1, ano, 20118

Ao ter claro estas ideias, os professores poderão proporcionar aos bebês, vivências que promovam a apropriação daquilo que não é biológico, uma segunda natureza. Para andar, falar, pensar como um ser humano, enfim, para objetivar as máximas possibilidades humanas, o bebê precisa estar inserido em um contexto que lhe propicie isso. Não há, dentre os espaços e instituições humanas, local mais privilegiado para isso do que a escola, mesmo que seus frequentadores sejam bebês. (SAVIANI, 2011). Escola aqui entendida como lócus privilegiado de socialização do conhecimento elaborado, independente da faixa etária (MARTINS 2009).

No cotidiano de uma creche, a todo o momento, pode-se observar indícios emitidos pelos bebês. Para apreender estas informações, faz-se necessário uma relação de interlocução entre o educador e o bebê. Não é possível contribuir com o desenvolvimento dos bebês desconsiderando sua necessidade interna e favorecendo sempre as mesmas experiências ou, ainda, a mesma cultura do lar. É preciso fazer mais, ir além, para que elas também possam conhecer mais e ir além. As discussões acerca do desenvolvimento infantil, presentes na teoria histórico-cultural, nos indicam que a criança se apropria da cultura humana por meio de mediação estabelecida com um adulto ou com outras crianças mais desenvolvidas. Por isso, mais uma vez enfatizamos o papel do professor na Educação Infantil, pois é ele quem exerce o papel de mediador dessa manifestação cultural essencial à aprendizagem e ao desenvolvimento da criança no espaço educativo. Para isto, é preciso haver rupturas em concepções históricas que colocam os bebês em patamares de incapazes, incompetentes e em estágio de preparação para a vida adulta.

Por fim, olhar e considerar os sinais dos bebês, é entendê-los como carregados de intenções, de um ser vivo ativo, com um desenvolvimento em movimento. Faz-se necessário conhecimentos sobre o curso do desenvolvimento infantil, as peculiaridades de cada idade, seus estágios e fases pois, caso contrário poderemos nos ater em uma captação e leitura de sinais a partir de uma visão doméstica, mística, religiosa, popular, folclórica, enfim, não científica.

\section{REFERÊNCIAS}


REVISTAELETROONICA

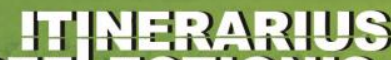

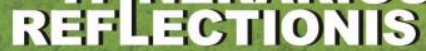

GRADUAÇ, AOO/PÓS-GRADUAÇÃO EM EDUCAÇ, AO

UFG / REJ

Volume, 14, n. 1, ano, 20118

ARCE A., SILVA J. C. É possível ensinar no berçário: o ensino como eixo articulador do trabalho com bebês ( 6 meses a 1 ano de idade). In ARCE A., MARTINS L. M.

Ensinando aos pequenos de zero a três anos. Editora Alínea, Campinas, 2009.

ÁVILA E. A. Premisas de la actividad com los objetos em el primer año de vida. In GOMÉZ A. MA. Et al. Estudio sobre las articularidades del desarrollo del niño préescolar cubano. Pueblo y Educación, Ciudad de La Habana, 2002.

BARBOSA, M. C. Especificidades da ação pedagógica com os bebês. In: Programa Currículo em Movimento. Disponível

em:http://portal.mec.gov.br/index.php?Itemid=1096\&id=15860\&option=com_content\& view=article. Acesso em: 05 dez. 2010.

BIRCHAL, P. de S. Exploração lúdica e afetividade em crianças de creche. Tese (Doutorado - Programa de Pós-Graduação em Psicologia. Área de Concentração: Psicologia Escolar e Desenvolvimento Humano - Instituto de Psicologia da Universidade de São Paulo, 2010.

BORGES, R. R. Curso de Extensão Universitária PROEPRE: contribuição para a formação de professores de creche. 2009. 327 f. Tese (Doutorado em Educação) Universidade Estadual de Campinas, 2009.

CAMPOS, M., M., FULLGRAF J., WIGGERS V. A qualidade da educação infantil brasileira: alguns resultados de pesquisa. Cadernos de Pesquisa, v. 36, n. 127, p. 87128, jan/abr, 2006. Disponível em: http://www.scielo.br/pdf/cp/v36n127/a0536127.pdf Acesso em: 12 de fevereiro de 2010.

COSTA, D. P. L. P. da. A influência de um programa de formação continuada no desempenho de profissionais de creches assistenciais com vistas à implantação do Proepre. Dissertação (Mestrado em Educação) - Universidade Estadual de Campinas, 2006.

DAGNONI A. P. R. Quais as fontes de saberes das professoras de bebês? Anais, $35^{\mathrm{a}}$ Reunião anual da Anped, Porto de Galinhas, 2012. Disponível em:

$<$ http://35reuniao.anped.org.br/images/stories/trabalhos/GT07\%20Trabalhos/GT071910_int.pdf> Acesso em: 02 maio 2014.

ELKONIN D. B. Psicologia do jogo. São Paulo: Martins Fones, 2009.

ELTINK C. F. Indícios utilizados por educadores para avaliar o processo de inserção de bebês em uma creche. Anais da 23ª Reunião anual da Anped, Caxambu 2000

Disponível em: <http://23reuniao.anped.org.br/textos/0709t.PDF>. Acesso em: 15 maio 2014.

FACCI, M. G. D. A periodização do desenvolvimento psicológico individual na perspectiva de Leontiev, Elkonin e Vigotski. Cadernos Cedes, Campinas, v. 24, n. 62, 
REVISTAELETROONICA

HUERARUS

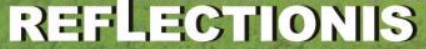

GRADUAÇ, AOO/PÓS-GRADUAÇÃO EM EDUCAÇ, AO

UFG / RE

Volume, 14, n. 1, ano, 20118

p. 64-81, abr, 2004. Disponível em: <http://www.cedes.unicamp.br>. Acesso em: 07 jun. 2010

DELGADO A. C. D. NORNBERG M. Do abrir-se aos pontos de vista e forças do desejo dos bebês e crianças bem pequenas. Linhas Críticas, Brasília, DF, v. 19, n. 38, p. 147-167, jan./abr. 2013. Disponível em:

http://periodicos.unb.br/index.php/linhascriticas/article/view/8924/6701 Acesso em: 04 de maio de 2015.

GOMES, C. A. V. O afetivo para a psicologia histórico-cultural: considerações sobre o papel da educação escolar. 2008. Tese (Doutorado em Educação) - Faculdade de Filosofia e Ciências, Universidade Estadual Paulista, Marília

V. O lugar do afetivo no desenvolvimento da criança: implicações educacionais. Psicologia em Estudo, Maringá, v. 18, n. 3, p. 509-518, jul./set. 2013. Disponível em: http://www.scielo.br/pdf/pe/v18n3/v18n3a11.pdf. Acesso em: 05 de jan 2017.

GÓMEZ A. M. S. Educa sua hijo. Um programa para la família. In GÓMEZ A. MA. Et al. Estudio sobre las articularidades del desarrollo del niño préescolar cubano.

Pueblo y Educación, Ciudad de La Habana, 2002.

GUIMARÃES, D. de O. Entre a instrução e o diálogo: a construção da identidade educacional das creches. Anais da 29a Reunião anual da Anped, Caxambú, 2006 Disponível em: <http://29reuniao.anped.org.br/trabalhos/trabalho/GT07-2328--Int.pdf> . Acesso em: 15 maio 2014.

No contexto da creche, o cuidado como ética e a potência dos bebês. Anais da $31^{a}$ Reunião anual da Anped, Caxambú, 2008. Disponível em: $<$ http://31reuniao.anped.org.br/1 trabalho/GT07-4807--Int.pdf >. Acesso em: 15 maio 2014.

LEONTIEV, A. N. Actividad, consciência y personalidade. Impreso, La Habana, 1981.

LURIA, A. R. O cérebro humano e a atividade consciente. (In) VIGOTSKI L. S., LURIA A. R., LEONTIEV A. N. Linguagem, desenvolvimento e aprendizagem. São Paulo, Ícone Editora, 11 a ed., trad. Maria da Pena Villa lobos, 2010.

MARTINS, L. M. O ensino e o desenvolvimento de crianças de zero a três anos. In ARCE A., MARTINS L. M. Ensinando aos pequenos de zero a três anos. Editora Alínea, Campinas, 2009.

O desenvolvimento do psiquismo e a educação escolar: contribuições à luz da psicologia histórico-cultural e da pedagogia histórico-crítica. Campinas, Autores Associados, 2013.

MENDES D. M. L. F. MOURA M. L. S. de. Expressões faciais de emoção em bebês: importância e evidências. Estudos e pesquisas em psicologia, UERJ, RJ, ano 9, n. 2, p. 
Volume, 14, n. 1, ano, 20118

307-327, $2^{\circ}$ sem. 2009. Disponível em:

http://www.revispsi.uerj.br/v9n2/artigos/pdf/v9n2a04.pdf Acesso em: 04 de maio de 2016.

MUKHINA, V. Psicologia da idade pré-escolar. São Paulo: Martins Fontes, 1996.

PANTALENA, E. S. O ingresso da criança na creche e os vínculos iniciais. Dissertação (Mestrado em Educação) - Faculdade de Educação da Universidade de São Paulo, 2010.

RAMOS T. K. G. Possibilidades de organização de práticas educativas na creche em parceria com os bebês: o que "dizem" as crianças? Anais, 34ª Reunião anual da Anped, Natal, 2011. Disponível em:

<http://34reuniao.anped.org.br/images/trabalhos/GT07/GT07-1092\%20int.pdf >. Acesso em: 14 maio 2014.

SAVIANI, D. Pedagogia histórico-crítica: primeiras aproximações. 11.ed.rev. Campinas, SP: Autores Associados, 2011.

SILVA, J. C. Práticas Educativas: a relação entre cuidar e educar e a promoção do desenvolvimento infantil à luz da Psicologia Histórico-Cultural. Dissertação (Mestrado em Educação Escolar) - Universidade Estadual Paulista, Faculdade de Ciências e Letras, Campus de Araraquara, 2008.

VYGOTSKI, L. S. Lev S. Vigotski: Manuscrito de 1929. Trad. de Alexandra Marenitch; Luís Carlos de Freitas; Angel Pino. Educação \& Sociedade, ano XXI, no 71, jul. de 2000. Disponível em: http://www.scielo.br/pdf/es/v21n71/a02v2171.pdf Acesso em 28 de nov de 2016.

Obras escogidas. Tomo IV. 2. ed. Madrid: Machado Libros. 2006.

ZAPORÓZHETS, A. V. Desarrollo psíquico del niño desde el nacimiento hasta el ingreso en la escuela. In: SMIRNOV, A. A. et al. Psicología. México: Editorial Grijalbo, 1960.

Importância dos períodos iniciais da vida na formação da personalidade infantil. In DAVIDOV, V. e SHUARE, M. (orgs) - La Psicologia Evolutiva y Pedagógica en la URSS (Antologia). Moscou: Editorial Progresso, 1987. 